\title{
Spectrum of Spinal Cord, Spinal Root, and Brain MRI Abnormalities in Congenital Zika Syndrome with and without Arthrogryposis
}

(D) M.F.V.V. Aragao, (D) A.M. Brainer-Lima, (D) A.C. Holanda, (DV. van der Linden, (DL. Vasco Aragão, (D) M.L.M. Silva Júnior, (DC. Sarteschi, (D) N.C.L. Petribu, and (D)M.M. Valença on $\equiv$

\begin{abstract}
BACKGROUND AND PURPOSE: Arthrogryposis is among the malformations of congenital Zika syndrome. Similar to the brain, there might exist a spectrum of spinal cord abnormalities. The purpose of this study was to explore and describe in detail the MR imaging features found in the spinal cords, nerve roots, and brains of children with congenital Zika syndrome with and without arthrogryposis.
\end{abstract}

MATERIALS AND METHODS: Twelve infants with congenital Zika syndrome (4 with arthrogryposis and 8 without) who had undergone brain and spinal cord MR imaging were retrospectively selected. Qualitative and quantitative analyses were performed and compared between groups.

RESULTS: At visual inspection, both groups showed reduced thoracic spinal cord thickness: $75 \%(6 / 8)$ of the group without arthrogryposis and $100 \%(4 / 4)$ of the arthrogryposis group. However, the latter had the entire spinal cord reduced and more severely reduced conus medullaris anterior roots (respectively, $P=.002$ and .007 ). Quantitative differences were found for conus medullaris base and cervical and lumbar intumescences diameters (respectively, $P=.008, .048, .008$ ), with more prominent reduction in arthrogryposis. Periventricular calcifications were more frequent in infants with arthrogryposis $(P=.018)$.

CONCLUSIONS: Most infants had some degree of spinal cord thickness reduction, predominant in the thoracic segment (without arthrogryposis) or in the entire spinal cord (with arthrogryposis). The conus medullaris anterior roots were reduced in both groups (thinner in arthrogryposis). A prominent anterior median fissure of the spinal cord was absent in infants without arthrogryposis. Brain stem hypoplasia was present in all infants with arthrogryposis, periventricular calcifications, in the majority, and polymicrogyria was absent.

ABBREVIATIONS: $A A C D=$ Association for Assistance of Disabled Children; $G R E=$ gradient recalled-echo; IgM = immunoglobulin M

$\mathrm{T}$ he Zika virus infection is transmitted by a bite from an infected mosquito, with Aedes aegypti being the main vector. ${ }^{1}$ Zika virus was first discovered in 1947 in monkeys in the Zika forest in Uganda, ${ }^{2}$ and human infection was identified in $1952 .{ }^{3}$

Received November 2, 2016; accepted after revision December 22.

From the Centro Diagnostico Multimagem (M.F.V.V.A.), Recife, Brazil; PROCAPE (A.M.B.-L.), University of Pernambuco, Recife, Brazil; Mauricio de Nassau University (M.F.V.V.A., A.M.B.-L.), Recife, Brazil; Federal University of Pernambuco (A.C.H., M.L.M.S.J., M.M.V.), Recife, Brazil; Association for Assistance of Disabled Children (V.v.d.L.), Recife, Brazil; Barão de Lucena Hospital (V.v.d.L., N.C.L.P.), Recife, Brazil; Prof Fernando Figueira Integral Medicine Institute (L.V.A.), Recife, Brazil; and Fundação Oswaldo Cruz-Fiocruz/PE (C.S.), Recife, Brazil.

Please address correspondence to M.F.V.V. Aragao, MD, Centro Diagnostico Multimagem, Rua Frei Matias Teves, 194-Ilha do Leite, Recife-PE, Brazil 50070-45; e-mail: fatima.vascoaragao@gmail.com

-- Indicates open access to non-subscribers at www.ajnr.org

三 Indicates article with supplemental on-line table.

http://dx.doi.org/10.3174/ajnr.A5125
The first epidemic of Zika virus occurred only in 2007 in Micronesia and the Yap Islands. ${ }^{4}$ The second epidemic was found in 2013, in French Polynesia, ${ }^{5}$ and the third began in Brazil, ${ }^{6,7}$ where it was initially detected in Bahia, Northeast Brazil, in March $2015 .^{6,8}$

In September 2015, a substantial increase in the incidence of infants with microcephaly was detected in northeast Brazil. ${ }^{8}$ For the first time, a strong increase of evidence suggested the association between the Zika virus infection outbreak and microcephaly by congenital infection. ${ }^{9}$ In Brazil, on December 31, 2016, there were 2366 cases of microcephaly and other central nervous system malformations suggestive of congenital Zika syndrome. ${ }^{10}$ There are 2 major lineages of Zika virus, the African, reported recently in Guinea-Bissau, and the Asian, reported from Asia and the West Pacific region to the Americas and Cabo Verde, which is the strain currently in Brazil. ${ }^{10}$ Neurologic complications have been related only to the Asian strains after 2007. ${ }^{10}$ The explanation as to why 
and how the Brazilian Zika virus strain could have developed this neurotropism for the central nervous system is still unknown.

The disease has already spread and, according to the World Health Organization, 76 countries and territories, particularly in Latin America, have reported evidence of transmission of the Zika virus by mosquitoes. Cases of microcephalic infants have been reported in 29 countries. ${ }^{10}$

In addition to microcephaly, other serious brain abnormalities were observed, especially brain calcifications, predominantly in the cortical and subcortical white matter junction, associated with malformations of cortical development (often polymicrogyria or pachygyria with predominant frontal lobe involvement) and a simplified cortical gyral pattern. Other frequent imaging findings are ventriculomegaly; decrease in brain, brain stem, and cerebellar volumes; enlargement of the cisterna magna and the extraaxial subarachnoid space; corpus callosum abnormalities (hypogenesis and hypoplasia); and delayed myelination. ${ }^{11}$

The congenital Zika syndrome is an entity without a well-known clinical spectrum, probably with only the most severe cases of the spectrum recognized. Other malformations have been described in some infants, such as ophthalmologic alterations ${ }^{12,13}$ and arthrogryposis. ${ }^{11,13,14}$ Currently, $8 \%$ of the children with presumed congenital Zika virus infection followed by the Association for Assistance of Disabled Children (AACD) in Recife, Brazil have arthrogryposis. Among the children with CSF immunoglobulin M (IgM) who tested positive for Zika virus, 6.6\% have arthrogryposis.

Arthrogryposis multiplex congenita, often known simply as arthrogryposis, is a syndrome characterized by joint contractures, present since birth, affecting $\geq 2$ areas of the body. ${ }^{15-20}$ These joint malformations can be attributed to different disorders, such as defects of uterine environment, disorders of connective tissues, muscular dystrophies, and other abnormalities or conditions that affect the central or peripheral nervous systems in at least one of the components of the motor pathways from the spinal cord to muscles. ${ }^{16,18}$ Regardless of the cause, children affected by arthrogryposis have onset and severe weakness early in intrauterine life, with immobilization of joints at different developmental stages. ${ }^{16}$

No study has yet analyzed qualitatively and quantitatively MR imaging of the spinal cord of children with congenital Zika syndrome, to our knowledge. Because there is a spectrum of congenital Zika syndrome for brain abnormalities, a similar spectrum might occur in the spinal cord. Therefore, the aim of this study was to explore and describe in detail the MR imaging features found in the spinal cord and nerve roots of infants with congenital Zika syndrome with or without arthrogryposis.

\section{MATERIALS AND METHODS}

This retrospective series included 12 infants diagnosed with congenital Zika syndrome, based on the Brazilian government proto$\mathrm{col}^{8}{ }^{8}$ who had or did not have arthrogryposis and met the following inclusion criteria: 1) brain imaging suggestive of any congenital infection; 2) a complete investigation with negative findings, including laboratory testing, of the other 6 main infectious causes of primary microcephaly (toxoplasmosis, cytomegalovirus, rubella, syphilis, herpes simplex, and HIV); 3) negative results of an investigation, through clinical examination and family history, for causes of microcephaly and brain calcifications such as prenatal and perinatal complications; exposure to licit and illicit drugs, toxic substances, and ionizing radiation; genetic and metabolic diseases; and congenital infections; and 4) the existence of previously performed brain and spinal cord MR imaging.

Since October 2015, infants with suspected microcephaly born in Pernambuco are reported on a government Web site (cievspe. $\mathrm{com} / \mathrm{microcefalia}$ ) by health professionals. The criterion for microcephaly up to December 2015 was a head circumference of $\leq 33 \mathrm{~cm}$. Therefore, all the infants born before December 2015, including all the ones included in this study, were referred for investigation of congenital Zika syndrome because they had a head circumference of up to $33 \mathrm{~cm}$ (currently, the criterion for microcephaly is based on the International Fetal and Newborn Growth Consortium for the 21st Century [INTERGROWTH21 st]). Once microcephaly was detected, the infants in this study were referred to the AACD, where they were evaluated, as needed, by a multidisciplinary team. The AACD has become one of the major referral centers in Pernambuco for the diagnosis and follow-up of children with microcephaly and congenital Zika syndrome.

Besides a noncontrast brain CT scan, obtained in all suspected cases of microcephaly as part of the government protocol, all infants in this study also underwent MR imaging, based on clinical evaluation. The major indications for brain MR imaging were the presence of refractory seizures or suspicion of hydrocephalus, while the major indications for spinal cord MR imaging were suspicions of arthrogryposis or the presence of early-onset abnormal posture of the limbs. A reduced essential protocol for neuroaxis MR imaging was created in our service with a reduced sedation time.

This retrospective study was approved by the Federal University of Pernambuco Research Ethical Committee, and the children's mothers or guardians gave their consent for the publication of the results and images. Infants included in this study were chosen by convenience, following the inclusion criteria. Up to the beginning of the study, 12 infants with congenital Zika syndrome (4 with arthrogryposis and 8 without it) had undergone, postnatally, brain and spinal cord MR imaging at our service.

Inclusion of controls was not possible because the techniques and section thickness of spinal MR imaging of infants up to 1 year found retrospectively at our service ( 5 cases) were different from the 12 already-included cases, making comparison very difficult. Nevertheless, a brief qualitative comparison, by visual inspection, was still performed (Fig 1).

MR imaging of the whole spinal cord was performed in all 12 children. All the images were T2-weighted. The protocol was optimized to decrease the examination time. Therefore, T1 was not performed in the spinal cord, and the duration of an MR imaging procedure for the brain and spinal cord was 50 minutes, approximately. Of the 12 children, 2 underwent MR imaging in a $1.5 \mathrm{~T}$ scanner (Intera; Philips Healthcare, Best, the Netherlands); and 10 , in a $1.5 \mathrm{~T}$ scanner (Signa HDxt; GE Healthcare, Milwaukee, Wisconsin). The 2 examinations performed in the Philips MR imaging scanner had technical parameters similar to those of the GE scanner, while measurements were performed on balanced fast-field echo sequences. No contrast was used in any of the infants, while sedation was necessary for all of them. Table 1 shows 


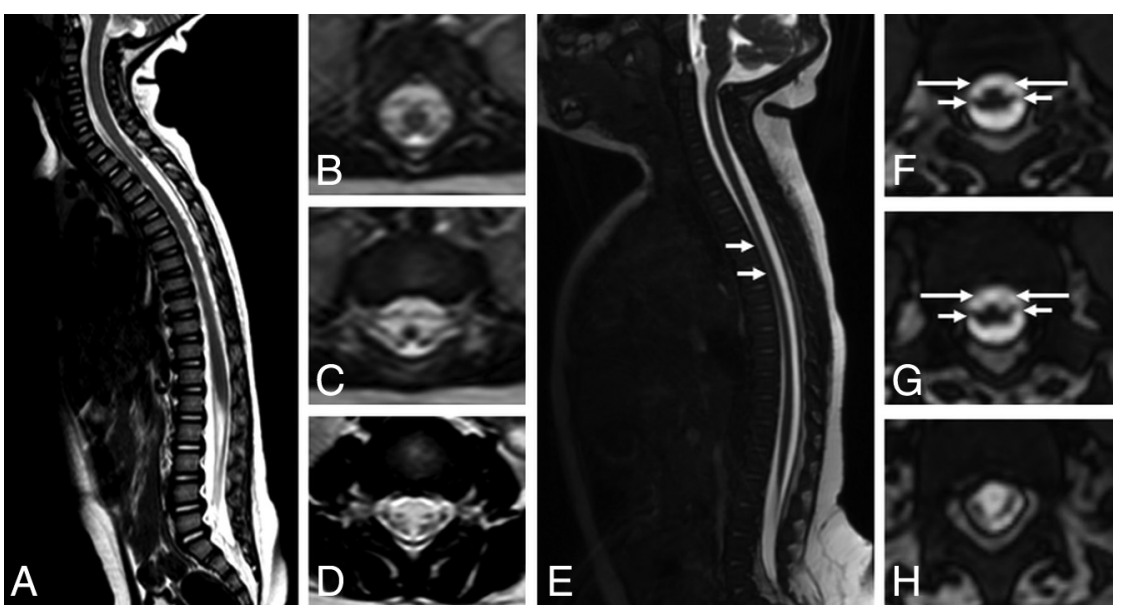

FIG 1. Comparison of spinal cord MR imaging between a control 12-month-old child $(A-D)$ and a 4-month-old infant with presumed congenital Zika syndrome and arthrogryposis (E-H). Sagittal T2 (A) shows a normal-sized spinal cord and conus medullaris and no abnormal signal. Axial reformatted T2 reveals symmetric and normal-sized anterior and posterior nerve roots in the conus medullaris ( $B$ and $C)$ and cauda equina $(D)$. Meanwhile, sagittal T2-weighted volumetric GRE image $(E)$ shows reduced spinal cord thickness, especially in the thoracic region (short white arrows). On the axial reconstruction of T2-weighted volumetric GRE $(F-H)$, we can observe reduction of the conus medullaris anterior roots (long arrows) compared with posterior roots (short arrows).

Table 1: MR imaging parameters for brain and spinal cord image acquisition for all of the participants

\begin{tabular}{|c|c|c|c|c|c|c|}
\hline \multirow[b]{2}{*}{ MRI Parameters } & \multicolumn{3}{|c|}{ Brain } & \multicolumn{3}{|c|}{ Spinal Cord } \\
\hline & $\begin{array}{l}\text { Axial 3D } \\
\text { SWAN }\end{array}$ & $\begin{array}{c}\text { Axial 3D } \\
\text { FSPGR }\end{array}$ & $\begin{array}{c}\text { Axial } \\
\text { T2*GRE }\end{array}$ & $\begin{array}{c}\text { Sagittal 3D } \\
\text { Volumetric } \\
\text { GRE }\end{array}$ & Coronal T2 & Axial T2 \\
\hline $\mathrm{TE}(\mathrm{ms})$ & 50 & Minimum & 645 & Minimum & 120 & 110 \\
\hline TR (ms) & 78.3 & - & 25 & - & 3700 & 5934 \\
\hline Flip angle & $15^{\circ}$ & $12^{\circ}$ & $15^{\circ}$ & $45^{\circ}$ & - & - \\
\hline Bandwidth (kHz) & 41.67 & 31.25 & 31.25 & 50 & 41 & 31.25 \\
\hline FOV $(\mathrm{cm})$ & 20 & 20 & 24 & 30 & 25 & 18 \\
\hline Section thickness (mm) & 3 & 2 & 5 & 0.8 & 4.5 & 4 \\
\hline Spacing $(\mathrm{mm})$ & - & - & 0.5 & - & 0.5 & 1 \\
\hline Frequency $(\mathrm{Hz})$ & 288 & 256 & 288 & 320 & 384 & 320 \\
\hline Phase & 224 & 256 & 192 & 320 & 224 & 224 \\
\hline NEX & - & 1 & 1 & 1 & 1 & 3 \\
\hline Frequency direction & AP & $\mathrm{AP}$ & $\mathrm{AP}$ & AP & $R-L$ & $\mathrm{AP}$ \\
\hline
\end{tabular}

Note:-AP indicates anteroposterior; R-L, right-left; FSPGR, fast-spoiled gradient recalled; SWAN, susceptibilityweighted angiography.

the parameters used for brain and spinal cord MR imaging. The images were analyzed and measured by 2 experienced neuroradiologists (M.F.V.V.A. and A.M.B.-L.), with the final interpretation determined by a consensus between them. Discrepancies between observers were not common, and when they occurred, they were resolved jointly after further review of the images.

Measurements of the spinal cord and spinal canal of these infants were taken by using the PACS software. To account for the spinal cord and spine curvatures, we performed all the measurements on sagittal images, as shown in Fig 2 (sagittal T2 volumetric gradient recalled-echo [GRE] image and balanced fast-field echo, respectively, in the GE Healthcare and Philips scanners).

The anatomic references for measurements of the spinal cord were the following: the smallest anteroposterior diameter of cervical, thoracic, and lumbar segments; and the largest anteroposterior diameter of the cervical and lumbar segments (ie, cervical and lumbar intumescences in adults are from about $\mathrm{C} 4$ to $\mathrm{T} 1$ and from $\mathrm{T} 9$ to $\mathrm{T} 12$, respectively) $)^{21}$ determined by visual inspection. The anteroposterior diameter of the conus medullaris base was also measured. It is defined as the inferior portion of the spinal cord, at the location where the spinal cord begin to reduce its thickness to form the conus medullaris. The medullaris cone is usually located, in infants, in the level of L2-L3 or above. ${ }^{22}$ Similarly, the vertebral canal was measured at approximately the same levels as the spinal cord measurements, to obtain a spinal cord/vertebral canal ratio for each measure of the spinal cord. These measurements were compared between children with and without arthrogryposis.

Other features of the spinal cord were qualitatively evaluated and compared between the 2 groups on axial T2 FSE or volumetric GRE and balanced fast-field echo reconstructions. The features evaluated in the axial plane were reduction of conus medullaris roots (graded as mild, moderate, and severe) and prominence of the anterior median fissure of the spinal cord (absent or present). On the sagittal plane, the thickness for each spinal cord segment (normal or decreased) was evaluated. The hip joints were assessed for developmental dysplasia on coronal FSE T2WI.

Additionally, brain MR imaging findings were compared between the 2 groups. We reviewed the MR images for the following: decreased brain volume (graded as mild, moderate, and severe); cerebral ventricular enlargement due to white matter hypoplasia; malformations of cortical development and sulcation and their locations; abnormalities of the corpus callosum (classified as agenesis, hypogenesis, and hypoplasia); myelination (normal or delayed, based on a previous study); the presence and location of brain calcifications; decreased brain stem and cerebellar volume; an enlarged cisterna magna; an enlarged anterior supratentorial subarachnoid space; and the presence of intraparenchymal cysts.

Symmetry of brain damage was also evaluated. It was determined by visual comparison between the cerebral hemispheres. The criteria used to describe pathologic asymmetry were those used in clinical practice, mainly ventricle size, sulci enlargement, cerebral lobe size, and spatial displacement of the left and right hemispheres with respect to each other. When the differences between the hemispheres were according to the normal pattern, even though they were not equally sized, the damage was considered symmetric.

\section{Statistical Analysis}

Absolute and percentage values were calculated to describe the qualitative variables and median and interquartile ranges for con- 

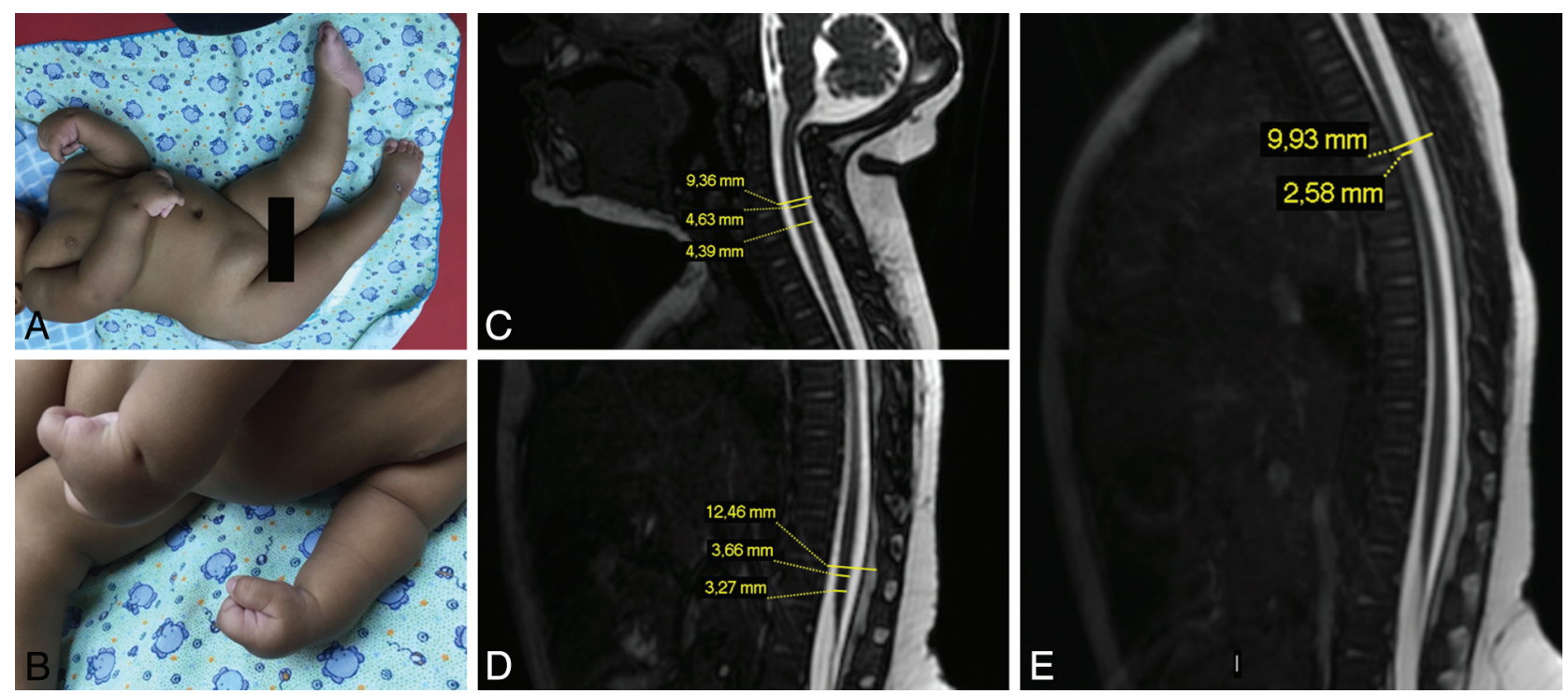

FIG 2. An infant with congenital Zika syndrome and arthrogryposis ( $A$ and $B$ ), with flexion contracture of the superior limbs, mainly of the wrists, hyperextension contracture of the lower limbs, and right hip deformity. Spinal cord MR imaging of an infant with arthrogryposis, showing spinal cord measurements $(C-E)$. Sagittal T2-weighted fast imaging using steady-state acquisition (volumetric GRE) shows the cervical ( $C$, from superior to inferior, vertebral canal diameter, largest cervical cord diameter, and smallest cervical cord diameter), lumbar ( $D$, from superior to inferior, vertebral canal diameter, largest lumbar cord diameter, and smallest lumbar cord diameter), and thoracic (E, from superior to inferior, vertebral canal diameter and smallest thoracic cord diameter) segments. There is apparently reduced spinal cord thickness, especially in the thoracic region $(E)$, and an enlarged cisterna magna $(C)$.

Table 2: Individual clinical data of the 12 infants, 8 without and 4 with arthrogryposis, included in the study

\begin{tabular}{|c|c|c|c|c|c|c|}
\hline No. & Sex & $\begin{array}{l}\text { Gestational } \\
\text { Age (wk) }\end{array}$ & $\begin{array}{c}\mathrm{HC} \text { at } \\
\text { Birth }(\mathrm{cm})\end{array}$ & $\begin{array}{c}\text { Mother's Rash } \\
\text { during Pregnancy }\end{array}$ & Joints Affected & $\begin{array}{l}\text { IgM ZIKV } \\
\text { CSF Status }\end{array}$ \\
\hline \multicolumn{7}{|c|}{$\begin{array}{l}\text { Congenital Zika syndrome } \\
\text { without arthrogryposis }\end{array}$} \\
\hline 1 & $\mathrm{~F}$ & 35 & 29.5 & $2 \mathrm{mo}$ & & Positive \\
\hline 2 & $M$ & 36 & 31.5 & $4 \mathrm{mo}$ & & No data \\
\hline 3 & $\mathrm{~F}$ & 40 & 30 & No rash & & No data \\
\hline 4 & $M$ & 39 & 26 & $3 \mathrm{mo}$ & & Positive \\
\hline 5 & M & 39 & 31 & $3 \mathrm{mo}$ & & Positive \\
\hline 6 & $\mathrm{~F}$ & 39 & 28.5 & $2.5 \mathrm{mo}$ & & Positive \\
\hline 7 & $M$ & 39 wk 5 days & 32 & $4 \mathrm{mo}$ & & Positive \\
\hline 8 & M & 39 wk 5 days & 28 & $3 \mathrm{mo}$ & & Positive \\
\hline \multicolumn{7}{|c|}{$\begin{array}{l}\text { Congenital Zika syndrome } \\
\text { with arthrogryposis }\end{array}$} \\
\hline 9 & $\mathrm{~F}$ & 37 & 29 & No rash & Feet, knees, hips, elbows, wrists, fingers & Positive \\
\hline 10 & M & 37 & 26 & $4 \mathrm{mo}$ & Feet, knees, hips, wrists, fingers & No data \\
\hline 11 & M & 40 & 27 & No rash & Feet, knees, hips & No data \\
\hline 12 & $\mathrm{~F}$ & 38 & 30 & $2 \mathrm{mo}$ & Feet, hips, wrists, fingers & Positive \\
\hline
\end{tabular}

Note:- $-\mathrm{HC}$ indicates head circumference; ZIKV, Zika virus.

${ }^{a}$ Test performed on the infant.

tinuous variables. For association, we used the Fisher exact test. The Mann-Whitney test was applied to compare continuous variables. A $P$ value $<.05$ was significant, while a $P$ value $<.1$ was considered a statistical trend. The authors opted to include the data with a statistical trend because it points to the possibility of finding statistically significant results if the sample size is increased. The statistical analyses were performed with the Statistical Package for Social Sciences software, Version 21.0 (IBM, Armonk, New York).

\section{RESULTS}

Of the analyzed sample of 12 children, 7 (58\%) were boys, and of the total, 4 (33\%) had arthrogryposis. Maternal mean age was $27.4 \pm 8.5$ years. Gestational age ranged from 35 to 40 weeks, with an average of $38.2 \pm 1.6$ weeks. Nine of the mothers reported a rash, $6(66.7 \%)$ in the first trimester and $3(33.3 \%)$ in the second trimester. Forty percent of girls in this study had arthrogryposis, while $29 \%$ of boys had arthrogryposis, with no statistical difference $(P=1.000)$. Table 2 shows the individual clinical data of the 12 children and the IgM CSF status positive for Zika virus for all 8 children tested. The mean age at MR imaging was 135.83 days (131.25 days for the arthrogryposis group and 138.16 days for the group without arthrogryposis). The On-line Table shows the individual radiologic data of the 12 children.

At visual inspection, both groups showed reduction of high thoracic spinal cord thickness: 75\% (6/8) without arthrogryposis and $100 \%(4 / 4)$ with arthrogryposis. The thoracic spinal cord 
segment was frequently the one most severely reduced, as shown in Table 3. Indeed, all children with arthrogryposis had more segments of the spinal cord affected and had severe reduction of the anterior nerve roots of the conus medullaris compared with the children without arthrogryposis, with statistical significance (respectively, $P=.002$ and .007). However, 6 of the children without arthrogryposis also had reductions of the anterior conus medullaris roots ( 4 had mild and 2 had moderate reduction), and 6 had congenital hip dysplasia. The groups were also found to be different, with a statistical trend $(P=.091)$, regarding the prominence of the anterior median fissure of the spinal cord, with none of the children without arthrogryposis having this feature.

Thus, in summary, the 4 infants with congenital Zika syndrome and arthrogryposis had, at visual inspection, reduced thickness of all segments of the spinal cord, with the thoracic segment its most compromised portion. All of them also had a severe reduction of the anterior nerve roots of the conus medullaris and congenital hip dysplasia. In addition, half of these infants

Table 3: Comparison between groups with and without arthrogryposis of features identified on MRI by visual inspection ${ }^{\mathrm{a}}$

\begin{tabular}{|c|c|c|c|}
\hline & $\mathrm{Ag}(n=4)$ & No $\mathrm{Ag}(n=8)$ & $P^{\mathrm{b}}$ \\
\hline \multicolumn{4}{|c|}{ Sites with spinal cord reduction } \\
\hline Absent & $0(0.0 \%)$ & $2(25.0 \%)$ & $.002^{\circ}$ \\
\hline Thoracic & $0(0.0 \%)$ & $5(62.5 \%)$ & \\
\hline Cervical, thoracic & $0(0.0 \%)$ & $1(12.5 \%)$ & \\
\hline $\begin{array}{l}\text { Cervical, thoracic, } \\
\text { conus medullaris }\end{array}$ & $4(100.0 \%)$ & $0(0.0 \%)$ & \\
\hline \multicolumn{4}{|c|}{$\begin{array}{l}\text { Site of most severe spinal } \\
\text { cord reduction }\end{array}$} \\
\hline Absent & $0(0.0 \%)$ & $2(25.0 \%)$ & $<.999$ \\
\hline Thoracic & $4(100.0 \%)$ & $6(75.0 \%)$ & \\
\hline \multicolumn{4}{|c|}{$\begin{array}{l}\text { Prominence of the anterior median } \\
\text { fissure of the spinal cord }\end{array}$} \\
\hline Absent & $2(50.0 \%)$ & $8(100.0 \%)$ & .091 \\
\hline Present & $2(50.0 \%)$ & $0(0.0 \%)$ & \\
\hline \multicolumn{4}{|c|}{$\begin{array}{l}\text { Reduction of the anterior nerve roots } \\
\text { of the conus medullaris }\end{array}$} \\
\hline No reduction & $0(0.0 \%)$ & $2(25.0 \%)$ & $.007^{c}$ \\
\hline Mild & $0(0.0 \%)$ & $4(50.0 \%)$ & \\
\hline Moderate & $0(0.0 \%)$ & $2(25.0 \%)$ & \\
\hline Severe & $4(100.0 \%)$ & $0(0.0 \%)$ & \\
\hline \multicolumn{4}{|c|}{ Congenital hip dysplasia } \\
\hline Absent & $0(0.0 \%)$ & $2(25.0 \%)$ & .515 \\
\hline Present & $4(100.0 \%)$ & $6(75.0 \%)$ & \\
\hline
\end{tabular}

Note:-Ag indicates arthrogryposis

a Data are number of patients (\%)

${ }^{\mathrm{b}} P=$ Fisher Exact test.

'Statistically significant. had a prominent anterior median fissure, a feature not identified in any of the children without arthrogryposis.

Overall, the anteroposterior diameters of different levels of the spinal cord were smaller in infants with arthrogryposis compared with those without (Table 4). Statistically significant differences were found between the children with and without arthrogryposis regarding the conus medullaris base and lumbar and cervical intumescence measurements (respectively, $P=.008, .008, .048$ ). In addition, a statistical trend was observed regarding the smallest cervical spinal cord diameter $(P=.073)$. No statistical difference was found in the smallest high thoracic spinal cord anteroposterior diameters between the 2 groups.

The anteroposterior diameter of the vertebral canal was statistically similar between the 2 groups. The ratio between the spinal cord diameters and these vertebral canal measurements, at similar levels of the spinal cord, revealed statistically significant differences in the conus medullaris base and the lumbar intumescence between children with and without arthrogryposis (respectively, $P=.016$ and .008) (Table 4).

Figures 3 and 4 show children with congenital Zika syndrome with arthrogryposis, while Fig 5 shows a child with congenital Zika syndrome without arthrogryposis. Reduced spinal cord thickness (Figs $3 D$ and $4 C$ ), severe reduction of anterior conus medullaris roots (Figs $3 E-G$ and $4 G,-H$ ), and congenital hip dysplasia (Fig 3I) were found in all children with arthrogryposis.

Statistically significant differences between the groups with and without arthrogryposis were found only in periventricular calcifications $(P=0.018)$ when brain abnormalities were compared, and only a statistical trend was observed for cerebellar or brain stem hypoplasia, cerebellar calcifications, and brain stem calcifications (Table 5); those findings were more frequent in infants with arthrogryposis than without it, being brain stem hypoplasia found in all 4 infants, and cerebellar hypoplasia in 2 of them. The cerebral damage was severe in all the children with arthrogryposis, while only 3 without

Table 4: Comparison between groups with and without arthrogryposis regarding the anteroposterior diameter at different levels of the spinal cord and as the ratio between the spinal cord and vertebral canal anteroposterior diameters ${ }^{a}$

\begin{tabular}{|c|c|c|c|c|c|c|}
\hline \multirow[b]{2}{*}{ AP Diameters (mm) } & \multicolumn{3}{|c|}{ Spinal Cord Measures } & \multicolumn{3}{|c|}{ Spinal Cord/Vertebral Canal Ratio } \\
\hline & $\mathrm{Ag}(n=4)$ & No $A g(n=8)$ & $P^{\mathrm{b}}$ & $\mathrm{Ag}(n=4)$ & No Ag $(n=8)$ & $P^{\mathrm{b}}$ \\
\hline \multicolumn{7}{|c|}{ Smallest spinal cord diameters } \\
\hline Cervical & $4.5(4.4-4.9)$ & $5.4(4.7-5.9)$ & .073 & $0.44(0.41-0.47)$ & $0.57(0.44-0.60)$ & .154 \\
\hline High thoracic & $3.6(2.8-4.2)$ & $3.9(3.6-4.5)$ & .214 & $0.39(0.29-0.41)$ & $0.39(0.34-0.46)$ & .570 \\
\hline Conus medullaris base & $4.3(3.5-4.8)$ & $6.3(5.7-6.5)$ & $.008^{\mathrm{c}}$ & $0.44(0.41-0.47)$ & $0.57(0.44-0.60)$ & $.016^{\mathrm{c}}$ \\
\hline \multicolumn{7}{|c|}{ Largest spinal cord diameters } \\
\hline Cervical intumescence & $4.7(4.5-5.0)$ & $5.6(5.4-6.2)$ & $.048^{\mathrm{c}}$ & $0.46(0.41-0.49)$ & $0.58(0.47-0.63)$ & .109 \\
\hline Lumbar intumescence & $5.0(3.9-5.8)$ & $7.3(7.1-7.5)$ & $.008^{\mathrm{c}}$ & $0.44(0.32-0.51)$ & $0.59(0.56-0.64)$ & $.008^{c}$ \\
\hline
\end{tabular}

Note:-AP indicates anteroposterior; Ag, arthrogryposis.

${ }^{a}$ Data are median (25th-75th percentile).

${ }^{\mathrm{b}} P=$ Mann-Whitney test.

c Statistically significant. 

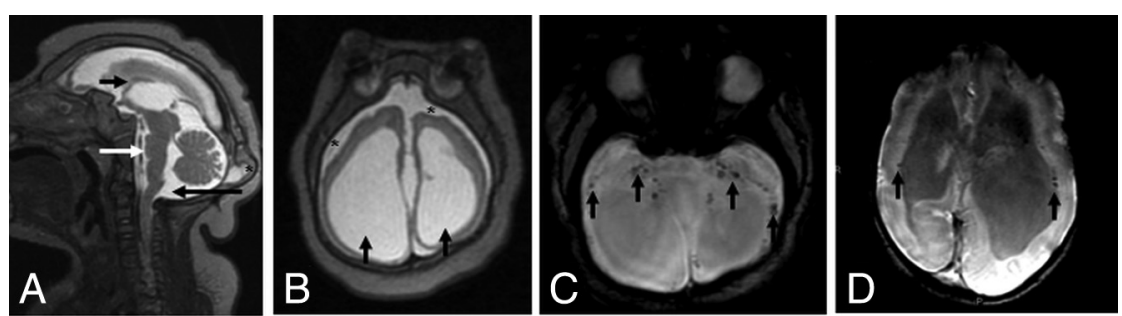

(1)
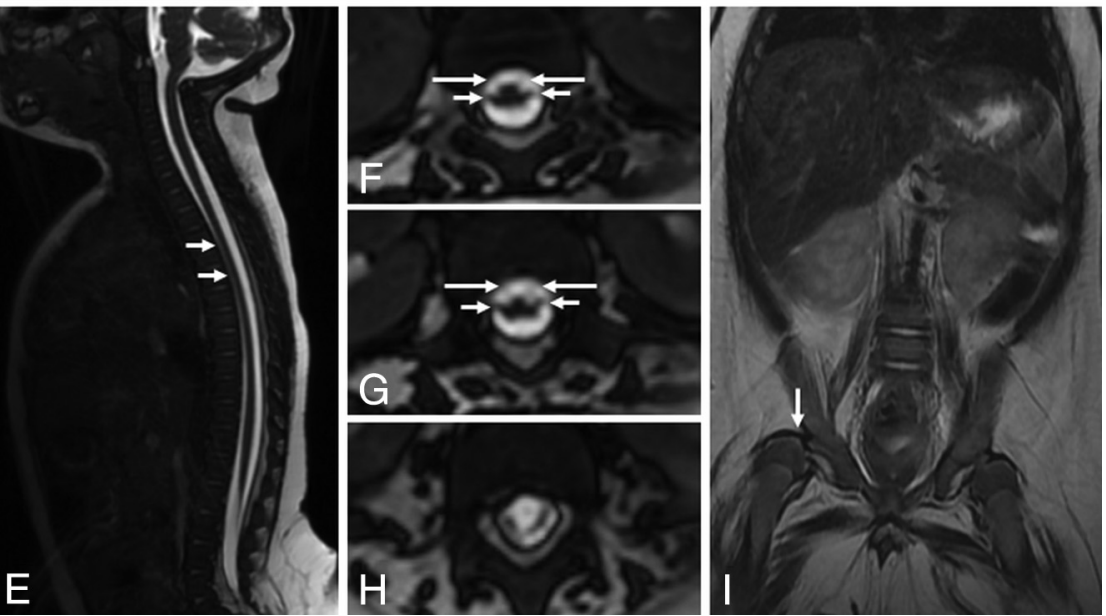

FIG 3. MR imaging of the brain and the spinal cord of an infant with microcephaly probably caused by congenital Zika virus infection, who has arthrogryposis. Sagittal T2-weighted image $(A)$ shows craniofacial disproportion, a hypogenetic corpus callosum (short black arrow), pons hypoplasia (white arrow), and a slightly enlarged cisterna magna (long black arrow). Note the lush external occipital protuberance (star). Axial T2-weighted image (B) shows an extremely simplified gyral pattern, a thin cortex with minimal sulcation, enlargement of the subarachnoid space (stars), and severe ventriculomegaly, mainly at the posterior horn (black arrows). Note small dystrophic calcifications, mainly at the basal ganglia and thalamus and in the junction between the cortical and subcortical white matter, and periventricular calcifications (black arrows) on T2-weighted SWI (C and D). Sagittal T2-weighted volumetric GRE $(E)$ shows reduced spinal cord thickness, especially in the thoracic region (white arrows). On the axial reconstruction of T2-weighted volumetric GRE $(F-H)$, we can observe reduction of the conus medullaris anterior roots (long arrows) compared with the posterior roots (short arrows), suggesting increased damage in the anterior-versus-posterior horns of the spinal cord. Coronal T2-weighted imaging (I) reveals congenital hip dysplasia, especially on the right side (white arrow)

arthrogryposis had severe damage, though there were no statistical differences between the groups.

Regarding malformations of cortical development, no statistical differences were found. None of the infants with arthrogryposis had polymicrogyria, while this malformation was present in 2 children without arthrogryposis $(P=.515)$. Pachygyria and a simplified gyral pattern were more often seen among the infants with arthrogryposis (both $P=.576$ ): One had diffuse pachygyria, one had diffuse simplified gyral pattern, and the other 2 had both malformations, with frontal pachygyria and a simplified parieto-occipital gyral pattern.

\section{DISCUSSION}

We analyzed the spinal cords of children with microcephaly with congenital Zika syndrome with and without arthrogryposis. Onethird of our sample had arthrogryposis, a figure that is not representative of the entire sample of patients with congenital Zika syndrome in the AACD.

By visual inspection, the arthrogryposis group had significant qualitative reduction of the entire spinal cord and severe reduction in the anterior conus medullaris roots. However, most of the children without arthrogryposis also had mild reduction of the anterior conus medullaris roots, and often just the thoracic spinal cord was reduced. This finding could explain the lack of statistical differences in the thoracic spinal cord segment between the groups evaluated in quantitative analysis.

Significant quantitative differences were found between the groups, with arthrogryposis showing a thinner conus medullaris base, lumbar intumescence, and cervical intumescence. The arthrogryposis group was also significantly thinner at the conus medullaris base and at the lumbar intumescence by the evaluation of ratios with the canal diameter (anteroposterior diameters of the spinal cord/vertebral canal).

These findings support the hypothesis that the congenital Zika syndrome has a disease-severity spectrum. The spectrum is not restricted to the brain, but a disease spectrum is also present in the spinal cord and spinal roots. Clinically, this spectrum would range from absent or mild manifestations to arthrogryposis. Thus, arthrogryposis would be the most severe extreme of the spectrum of spinal cord damage, with thinner thickness of the entire spinal cord and severe anterior nerve root reduction. However, the MRIs of infants without arthrogryposis have also demonstrated some grade of damage in the spinal cord, mainly in the thoracic segment, with some mild anterior spinal root reduction.

Our study has no control group for quantitative analysis. In addition, we have found no references in the literature to normal spinal cord measurements in infants. The control group is a group difficult to obtain retrospectively, especially with the same MR imaging technique for accurate comparison.

Arthrogryposis has been associated with microcephaly in the spectrum of congenital Zika virus infection. ${ }^{11,13,14}$ Schuler-Faccini et $\mathrm{al}^{14}$ identified arthrogryposis in 4 of 27 children, while Oliveira Melo et $\mathrm{al}^{13}$ mentioned 1 child with the condition. In addition, Melo et $\mathrm{al}^{23}$ also described 3 neonates who died shortly after birth. The MR imaging findings in arthrogryposis were recently reported, but that series of cases did not evaluate the spinal cord of infants without arthrogryposis. ${ }^{24}$ This study identified apparently reduced spinal cord thickness and reduced ventral roots in comparison with the dorsal roots. ${ }^{24}$ Regarding neurogenic arthrogryposis in patients without congenital Zika virus infection, Fedrizzi et $\mathrm{al}^{17}$ described brain and spinal cord MR imaging findings in 10 patients without an identified etiology.

The histopathologic changes in neurogenic arthrogryposis are dysgenesis of the anterior medullary horns and cytoarchitectural disorganization, which are more prominent in cervical and lum- 

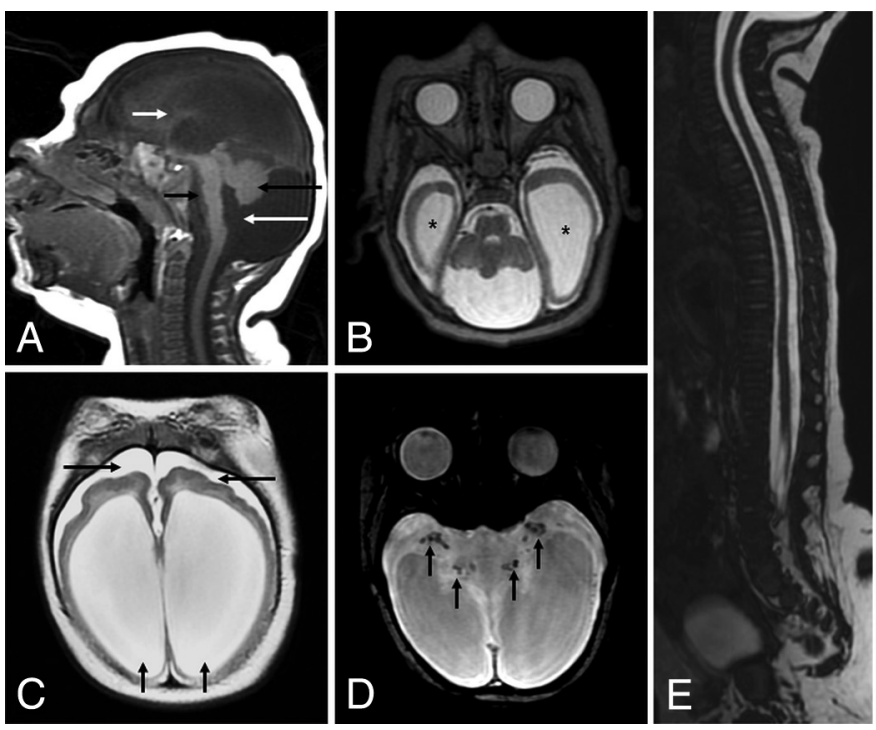

FIG 4. MR imaging of the brain and the spinal cord of an infant with microcephaly probably caused by congenital Zika virus infection who has arthrogryposis. Sagittal T1-weighted image $(A)$ shows severe microcephaly, brain stem (short black arrow) and severe cerebellar (long black arrow) hypoplasia, and an enlarged posterior fossa with a very enlarged cisterna magna communicating with the fourth ventricle (long white arrow). Note the extremely hypogenetic corpus callosum (small white arrow). Axial T2-weighted images ( $B$ and $C$ ) show severe ventriculomegaly and enlargement of temporal horns (stars) and other parts of the lateral ventricles, mainly at the posterior horn and ventricular atrium (short black arrows). Note the bulging walls of the ventricle and a simplified gyral pattern with minimal sulcation and slight enlargement of the subarachnoid space (long black arrows). Also, note small dystrophic calcifications mainly seen at the basal ganglia and thalamus (black arrows) on T2-weighted SWI (D). Sagittal T2-weighted volumetric GRE(E) shows thin spinal cord thickness, and axial reconstruction of T2-weighted volumetric GRE reveals a prominent anterior median fissure of the spinal cord $(F)$ and symmetric reduction of the conus medullaris anterior roots (long arrows) compared with posterior roots (short arrows), with damage affecting the anterior cord, preferentially ( $G$ and $H$ ).

bosacral intumescences associated with motor function. ${ }^{16}$ Histopathologic evaluation of the spinal cord of an infant with congenital Zika syndrome and arthrogryposis revealed fewer motor neurons than expected, even though transverse spinal cord sections could not be obtained. ${ }^{23}$ In addition, the brain stem had nerve cell degeneration and coarse and filamentous calcifications, while the cerebellum was hypoplastic and had focal cortical dysplasia. $^{23}$

The above-mentioned features were previously suggested by brain and spinal MR imaging evaluation of infants with arthrogryposis and reported by the authors ${ }^{24}$ and are consistent with what was found in the present study, reinforcing MR imaging being able to demonstrate the physiopathology of the congenital Zika syndrome. In this context, Zika virus probably has a tropism for the brain and also for the motor spinal cord neurons, which could occur initially in the thoracic region and achieve cervical and lumbar intumescences and conus medullaris in more severe cases.

Tropism of the Zika virus for neurons, leading eventually to their death, has been shown in the literature. ${ }^{23}$ The morphologic brain alterations with multiple calcifications, mainly in the junction between the cortical and subcortical white matter, induced by the Zika virus, suggest serious damage that may cause sudden arrest in the development of the nervous system, resulting in a simplified pattern of cortical circumvolutions, malformations of cortical development (mainly in the frontal lobes), associated with ventriculomegaly, and corpus callosum and brain stem hypoplasia. ${ }^{11,13,25,26}$ Long tract and spinal cord neuron alterations
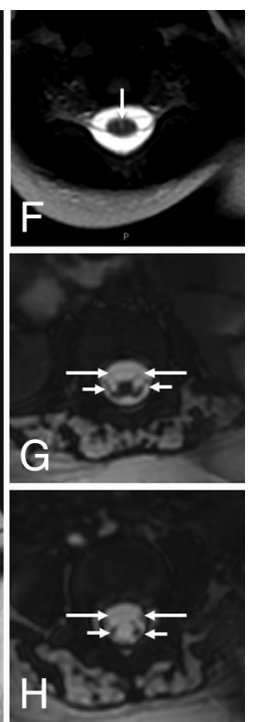

may occur in congenital Zika virus infection, even in patients without arthrogryposis. This hypothesis is supported by Mlakar et $\mathrm{al}^{26}$ who described infant brain abnormalities and Wallerian degeneration in the descending tracts of the brain stem and spinal cord, while the ascending tracts of the dorsal columns were well-preserved, in a 32-week-old fetus with confirmed real-time polymerase chain reaction for Zika virus infection without arthrogryposis.

In our study, the arthrogryposis group showed significantly more frequent periventricular calcifications and a trend toward more frequent cerebellar and brain stem hypoplasia and calcifications. One hypothesis that could be taken from these data is that the Zika virus damage to the human neural progenitor cells ${ }^{27}$ in the periventricular zone will be more pronounced in children with arthrogryposis. Another possible explanation is major damage in the basal ganglia and pyramidal tracts, which could lead to or be associated with brain stem and cerebellar hypoplasia and spinal cord abnormalities. We hypothesized that both primary and secondary damage to the spinal cord are possible. We observed that the virus probably has great tropism for motor neurons, both in the brain (frontal lobes) and spinal cord (ventral spinal cord). In this context, MR imaging is important in understanding the physiopathology of congenital Zika syndrome and clarifying that the joint malformations found in these children are due to the virus tropism for specific motor neurons in related areas of the brain stem, cerebellum, and spinal cord and not to direct action of the virus in the osteoarticular system.

Although without significance, the overall brain damage caused by the Zika virus was more pronounced in the arthrogryposis group. Another interesting observation is that polymicrogyria was absent in the 4 children with arthrogryposis, while pachygyria was present in almost all the infants with arthrogryposis. Polymicrogyria is a feature related to an interruption in the late stages of neuronal migration and cortical organization that originates only after the twentieth gestational week, ${ }^{28}$ while pachygyria is believed to originate in the early phase of pregnancy, between the twelfth and sixteenth gestational weeks. ${ }^{28}$ These data can indicate that congenital Zika syndrome with arthrogryposis is more often associated with earlier fetal infection, further supported by the more severe damage found in these infants. However, we did not find an association of the type of malformation of cortical development with the time of the mother's rash.

Nevertheless, the literature has shown that there is an interval between the maternal infection and the sonographic evidence of fetal abnormalities from 2 to 27 weeks. ${ }^{23}$ We suppose that the month of the mother's rash does not necessarily indicate exactly 

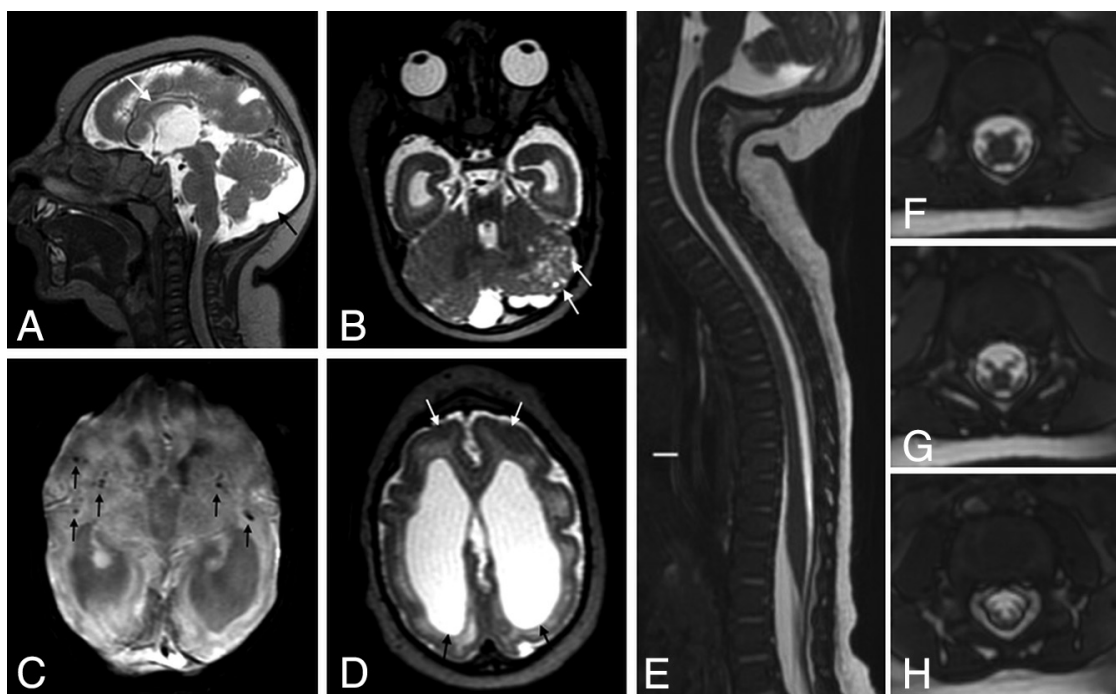

FIG 5. MR imaging of the brain and the spinal cord of an infant with microcephaly confirmed to be caused by the Zika virus without arthrogryposis. Sagittal T2-weighted images $(A)$ shows hypogenesis of the corpus callosum (white arrow) and an enlarged cisterna magna (black arrow). Coronal T2-weighted image (B) shows left cerebellar hemisphere hypoplasia, with cortical malformation and microcysts (white arrows). Axial SWI (C) shows small dystrophic calcifications in the junction between the cortical and subcortical white matter and in the basal ganglia (black arrows). Axial T2-weighted image $(D)$ shows a simplified gyral pattern, bilateral cortical thickness in the pachygyric frontal lobe (white arrows), and ventriculomegaly (black arrows). The spinal cord and conus medullaris are normal-sized and show no abnormal signal on the sagittal T2-weighted volumetric GRE (E). Axial reformatted T2weighted volumetric GRE reveals normal-sized anterior and posterior nerve roots in the conus medullaris ( $F$ and $G$ ) and cauda equina $(H)$.

Table 5: Comparison between children with and without arthrogryposis regarding some of the brain abnormalities found on $\mathrm{MRI}^{\mathrm{a}}$

\begin{tabular}{|c|c|c|c|}
\hline \multirow[b]{2}{*}{ Variables } & \multicolumn{2}{|c|}{ Arthrogryposis } & \multirow[b]{2}{*}{$P^{\mathrm{b}}$} \\
\hline & No $(n=8)$ & Yes $(n=4)$ & \\
\hline Decreased brain volume & $6(75.0 \%)$ & $4(100.0 \%)$ & .515 \\
\hline \multicolumn{4}{|l|}{ Grade of brain volume decrease } \\
\hline Mild & $1(20.0 \%)$ & $0(0.0 \%)$ & .876 \\
\hline Moderate/severe & $4(80.0 \%)$ & $3(100.0 \%)$ & \\
\hline Degree of cerebral damage & & & .394 \\
\hline Absent & $1(12.5 \%)$ & $0(0.0 \%)$ & \\
\hline Mild & $2(25.0 \%)$ & $0(0.0 \%)$ & \\
\hline Moderate & $2(25.0 \%)$ & $0(0.0 \%)$ & \\
\hline Severe & $3(37.5 \%)$ & $4(100.0 \%)$ & \\
\hline Symmetry & $6(75.0 \%)$ & $3(75.0 \%)$ & $>.999$ \\
\hline \multicolumn{4}{|l|}{ Cortical development abnormalities } \\
\hline Pachygyria & $3(37.5 \%)$ & $3(75.0 \%)$ & .545 \\
\hline Polymicrogyria & $2(25.0 \%)$ & $0(0.0 \%)$ & .515 \\
\hline Simplified gyral pattern & $4(50.0 \%)$ & $3(75.0 \%)$ & .576 \\
\hline Corpus callosum & & & $>.999$ \\
\hline Normal & $2(25.0 \%)$ & $0(0.0 \%)$ & \\
\hline Hypogenesis & $5(62.5 \%)$ & $3(75.0 \%)$ & \\
\hline Hypoplasia & $1(12.5 \%)$ & $1(25.0 \%)$ & \\
\hline Cortical and subcortical junction calcifications & $7(85.5 \%)$ & $4(100.0 \%)$ & $>.999$ \\
\hline Basal ganglia calcifications & $3(37.5 \%)$ & $3(75.0 \%)$ & .545 \\
\hline Periventricular calcifications & $0(0.0 \%)$ & $3(75.0 \%)$ & $.018^{\mathrm{c}}$ \\
\hline Brain stem calcifications & $1(12.5 \%)$ & $3(75.0 \%)$ & .067 \\
\hline Cerebellum calcifications & $0(0.0 \%)$ & $2(50.0 \%)$ & .091 \\
\hline Cerebellum or brain stem hypoplasia & $2(25.0 \%)$ & $4(100.0 \%)$ & .061 \\
\hline Increased cisterna magna & $8(100.0 \%)$ & $4(100.0 \%)$ & - \\
\hline Delayed myelination & $5(50.0 \%)$ & $4(100.0 \%)$ & .208 \\
\hline
\end{tabular}

${ }^{a}$ Data are number of patients (\%).

${ }^{\mathrm{b}} P=$ Fisher Exact test. when the embryo or fetus was infected, whether early or late during infection of the mother in the pregnancy.

On the basis of the findings described in this study, it is important to consider Zika virus infection in the differential diagnosis of congenital spinal cord and anterior nerve root diseases if the infant and mother have a positive epidemiologic context. This is especially important in mild cases in which microcephaly is absent and the only clinical manifestation is, for example, abnormal joints. On the other hand, health professionals should pay close attention during the follow-up of children from an epidemic area with mild or no clinical signs of spinal cord and anterior nerve root damage because they could possibly have future problems in their neuropsychomotor development. This can also be true for children without microcephaly, born in regions with the Zika virus epidemic.

It is difficult to determine the prognosis of the different degrees of the congenital Zika syndrome due to the lack of follow-up studies ${ }^{29}$; however, congenital Zika virus infection with severe brain damage should have a poor prognosis. ${ }^{29}$ Knowledge of the spectrum of this syndrome can be helpful in identifying which cases could have higher chances of worse outcomes. It is probable that infants with arthrogryposis will have worse prognoses, especially in motor development, even if they do not have severe brain lesions or microcephaly.

Despite the limitations, especially regarding the small number of patients and lack of a control group for quantitative analysis, this study is the first to analyze spinal cord MR imaging abnormalities in children with congenital Zika virus infection without arthrogryposis. In addition, this study raises the alarming hypothesis that children without clear signs of impairment (eg, microcephaly and arthrogryposis) can have brain and spinal cord imaging abnormalities probably caused by the Zika virus, a possibility that is starting to be seen in clinical practice.

The 8 children with congenital Zika syndrome without arthrogryposis did not have this major clinical manifestation of spinal cord impairment but had mild radiologic spinal cord abnormalities, such as a qualitative decrease in 
spinal cord thickness, especially at the thoracic segment, and mildly reduced anterior nerve roots at the conus medullaris. Therefore, we can suppose that there are, currently unidentified in the normal population of the epidemic area, more children with a mild degree of damage not only in the brain but also in the spinal cord. The identified cases could correspond to only the "tip of the iceberg," represented by microcephaly and arthrogryposis, of the congenital Zika syndrome.

\section{CONCLUSIONS}

Most of the infants with congenital Zika syndrome had some degree of spinal cord thickness reduction, which is predominant in the thoracic segment in cases without arthrogryposis and in the entire spinal cord in cases with arthrogryposis. In addition, there is thickness reduction of anterior nerve roots of the conus medullaris in both groups, being more severe in infants with arthrogryposis. With regard to brain lesions, periventricular calcifications were more frequent in infants with arthrogryposis. Although without statistical significance, the prominence of the anterior median fissure of the spinal cord was found only in infants with arthrogryposis; brain stem hypoplasia was present in all infants with arthrogryposis; brain stem and cerebellum calcifications were more frequent; and polymicrogyria was absent in this group.

\section{ACKNOWLEDGMENTS}

We are especially grateful to the anesthesiology staff, Drs Antonio Monteiro and Cristovam A. de Lira Terceiro; the neuropediatrician, Dr Ana van der Linden; the medical student, Julia Sales Machado; the MR imaging technician, Edineide Cristina Leite Lopes; and the Centro Diagnostico Multimagem for their help.

\section{REFERENCES}

1. Dick GW, Kitchen SF, Haddow AJ. Zika virus. I: isolations and serological specificity. Trans R Soc Trop Med Hyg 1952;46:509-20 CrossRef Medline

2. Dick GW. Zika virus, II: pathogenicity and physical properties. Trans R Soc Trop Med Hyg 1952;46:521-34 CrossRef Medline

3. Macnamara FN. Zika virus: a report on three cases of human infection during an epidemic of jaundice in Nigeria. Trans $R$ Soc Trop Med Hyg 1954;48:139-45 CrossRef Medline

4. Duffy MR, Chen TH, Hancock WT, et al. Zika virus outbreak on Yap Island, Federated States of Micronesia. N Engl J Med 2009;360: 2536-43 CrossRef Medline

5. Cauchemez S, Besnard M, Bompard P, et al. Association between Zika virus and microcephaly in French Polynesia, 2013-15: a retrospective study. Lancet 2016;387:2125-32 CrossRef Medline

6. Campos GS, Bandeira AC, Sardi SI. Zika virus outbreak, Bahia, Brazil. Emerg Infect Dis 2015;21:1885-86 CrossRef Medline

7. Cardoso CW, Paploski IA, Kikuti M, et al. Outbreak of exanthematous illness associated with Zika, Chikungunya, and Dengue Viruses, Salvador, Brazil. Emerg Infect Dis 2015;21:2274-76 CrossRef Medline

8. Ministério da Saúde (Brazil). Protocolo de vigilância e resposta à ocorrência de microcefalia e/ou alterações do sistema nervoso central (SNC). March 10, 2016. http://combateaedes.saude.gov.br/images/ sala-de-situacao/Microcefalia-Protocolo-de-vigilancia-e-resposta-10 mar2016-18h.pdf. Accessed December 19, 2016
9. Brito C. Zika virus: a new chapter in the history of medicine. Acta Med Port 2015;28:679-80 Medline

10. World Health Organization. Situation Report. Zika virus, microcephaly, Guillain-Barre syndrome. February 2, 2017. http://apps.who.int/iris/ bitstream/10665/254507/1/zikasitrep2Feb17-eng.pdf. Accessed February 8,2017

11. de Fatima Vasco Aragao M, van der Linden V, Brainer-Lima AM, et al. Clinical features and neuroimaging (CT and MRI) findings in presumed Zika virus related congenital infection and microcephaly: retrospective case series study. BMJ 2016;353:i1901 CrossRef Medline

12. Ventura CV, Maia M, Ventura BV, et al. Ophthalmological findings in infants with microcephaly and presumable intra-uterus Zika virus infection. Arq Bras Oftalmol 2016;79:1-3 CrossRef Medline

13. Oliveira Melo AS, Malinger G, Ximenes R, et al. Zika virus intrauterine infection causes fetal brain abnormality and microcephaly: tip of the iceberg? Ultrasound Obstet Gynecol 2016;47:6-7 CrossRef Medline

14. Schuler-Faccini L, Ribeiro EM, Feitosa IM, et al; Brazilian Medical Genetics Society-Zika Embryopathy Task Force. Possible association between Zika virus infection and microcephaly: Brazil, 2015. MMWR Morb Mortal Wkly Rep 2016;65:59-62 CrossRef Medline

15. Bamshad M, Van Heest AE, Pleasure D. Arthrogryposis: a review and update. J Bone Joint Surg Am 2009;91(suppl 4):40-46 CrossRef Medline

16. Banker BQ. Arthrogryposis multiplex congenita: spectrum of pathologic changes. Hum Pathol 1986;17:656-72 CrossRef Medline

17. Fedrizzi E, Botteon $G$, Inverno $M$, et al. Neurogenic arthrogryposis multiplex congenita: clinical and MRI findings. Pediatr Neurol 1993; 9:343-48 CrossRef Medline

18. Gordon N. Arthrogryposis multiplex congenita. Brain Dev 1998;20: 507-11 CrossRef Medline

19. Kalampokas E, Kalampokas T, Sofoudis C, et al. Diagnosing arthrogryposis multiplex congenita: a review. ISRN Obstet Gynecol 2012: 264918 CrossRef Medline

20. Mennen U, van Heest A, Ezaki MB, et al. Arthrogryposis multiplex congenita. J Hand Surg Br 2005;30:468-74 CrossRef Medline

21. Yousem D, Grossman R. Anatomy and degenerative diseases of the spine. In: Neuroradiology: The Requisites. 3rd ed. Philadelphia: Mosby/Elsevier; 2010:515-42

22. Wilson DA, Prince JR. John Caffey award. MR imaging determination of the location of the normal conus medullaris throughout childhood. AJR Am J Roentgenol 1989;152:1029-32 CrossRef Medline

23. Melo AS, Aguiar RS, Amorim MM, et al. Congenital Zika virus infection: beyond neonatal microcephaly. JAMA Neurol 2016;73: 1407-16 CrossRef Medline

24. van der Linden V, Filho EL, Lins OG, et al. Congenital Zika syndrome with arthrogryposis: retrospective case series study. $B M J$ 2016;354:i3899 CrossRef Medline

25. Hazin AN, Poretti A, Turchi Martelli CM, et al. Computed tomographic findings in microcephaly associated with Zika virus. $N E n g l$ J Med 2016;374:2193-95 CrossRef Medline

26. Mlakar J, Korva M, Tul N, et al. Zika virus associated with microcephaly. N Engl J Med 2016;374:951-58 CrossRef Medline

27. Tang H, Hammack C, Ogden SC, et al. Zika virus infects human cortical neural progenitors and attenuates their growth. Cell Stem Cell 2016;18:587-90 CrossRef Medline

28. Barkovich AJ, Gressens P, Evrard P. Formation, maturation, and disorders of brain neocortex. AJNR Am J Neuroradiol 1992;13: 423-46 Medline

29. Vouga M, Baud D. Imaging of congenital Zika virus infection: the route to identification of prognostic factors. Prenat Diagn 2016;36: 799-811 CrossRef Medline 